\title{
Obesity, a burning problem
}

\author{
${ }^{1,}$ Dr. Arunima Chaudhuri, ${ }^{2,}$ Dr. Amit Kumar Bandopadhyay \\ ${ }^{1}$ Assistant Professor, Department of Physiology, Burdwan Medial College, Burdwan 713104, West Bengal, \\ India. \\ ${ }^{2}$ Professor and Head of the Department of Anaesthesiology, Burdwan Medial College, Burdwan 713104, West \\ Bengal, India.
}

\begin{abstract}
Obesity, one of the greatest public health challenges of $21^{\text {st }}$ century, is related to several chronic conditions such as type II diabetes, hypertension, dyslipaedaemia and cardiovascular diseases and renal pathologies. Individuals with increased abdominal obesity are found to have an atherogenic triad, associated with adverse cardiovascular outcomes. Human obesity is characterized by marked sympathetic activation. Adiposity is associated with chronic low-grade systemic as well as inflammation of the hypothalamus. In women, early onset of obesity favors the development infertility in the adult age. In men, obesity is associated with low testosterone levels, reduced spermatogenesis and erectile dysfunction. Lifestyle modifications, drugs \& surgical intervention may prove to be fruitful in treatment of obesity.
\end{abstract}

Keywords: Obesity, health hazards.

\section{INTRODUCTION:}

One of the greatest public health challenges in the first half of $21^{\text {st }}$ century is preventing the epidemic of obesity. In India obesity is most prevalent in urban populations ( $\mathrm{male}=5.5 \%$, female $=12.6 \%)$, followed by the urban slums $(\mathrm{male}=$ $1.9 \%$, female $=7.2 \%$ ). Obesity rates are the lowest in rural populations (male $=1.6 \%$, female $=3.8 \%)$. Obesity has reached epidemic proportions in India , with morbid obesity affecting 5\% of the country's population. Socioeconomic class has an effect on the rate of obesity. As populations become more westernized, concerns about an obesity epidemic are on rise ${ }^{1,2}$.

\section{CLASSIFICATION OF OBESITY:}

Body mass index (BMI) is used by the National Institutes of Health's (NIH) to classify obesity, while the World Health Organization (WHO), uses body fat percentage. Using race or ethnic-specific BMI cut-off values can more accurately identify obesity in a population than the existing classification system ${ }^{3,4}$. For Asians population the values of BMI have been reset as their body composition is different from that of the western world ${ }^{5}$. Proposed classification of weight by BMI in adult Asians: Underweight < 18.5; Normal range: 18.5 - 22. 9; Overweight > 23; Obese I: 25 - 2 9. 9; Obese II > 30.

MRI and Bioelectric Impedance Analyzer for measuring body fat percentage have proven to be more useful. Based on cross-sectional analyses, it has been suggested that hip circumference divided by height (1.5) minus 18 (the body adiposity index, BAI), could directly estimate percent body fat without the need for further correction for sex or age. But other studies showed that estimates based on BAI are not more accurate than those based on BMI, waist circumference, or hip circumference ${ }^{6}$.

\section{OBESITY AND HEALTH HAZARDS:}

Obesity is related to type II diabetes, hypertension, dyslipaedaemia and cardiovascular diseases (CVD) ${ }^{1,2,3,7,8}$. The endocannabinoid system (ECS) is involved in lipid metabolism and obesity. In obese individuals blood concentrations of the endocannabinoids anandamide (AEA), 2 arachidonoylglcyerol (2-AG), fatty acid amide hydrolase (FAAH) and monoacylglycerol lipase (MGL) changes. FAAH activity in subcutaneous adipocytes increases with BMI ${ }^{9,10 .}$ Polymorphism of 385 C/A of FAAH is associated with overweight and obesity while mutations have been found to improve cardiovascular profile ${ }^{10}$. Adiposity is associated with chronic low-grade systemic inflammation as well as increased inflammation of the hypothalamus. Inflammation of hypothalamus may reduce the integrity of structures involved in reward and feeding behaviours ${ }^{8}$ and this may alter the feeding behaviors.

In women, early onset of obesity favors the development infertility in the adult age. Obesity in women can also increase risk of miscarriages and impair the outcomes of assisted reproductive technologies and pregnancy. Polycystic ovary syndrome (PCOS) is the most common cause of infertility, affecting up to one in 10 women ${ }^{3,11}$. Insulin resistance, marked by persistently elevated insulin, abnormal regulation of blood sugar and insensitivity to insulin in the liver and muscle cells, occurs in PCOS. The pituitary gland actively responds to chronically high insulin levels, triggering a cascade of hormonal changes that disrupt ovarian function and impair fertility. With increased circulating insulin levels, the gonadotrophs in obesity start pumping out large amounts of LH, thus disrupting ovulation ${ }^{11}$. In men, obesity is associated with low testosterone levels, reduced spermatogenesis and erectile dysfunction ${ }^{3,11}$. 


\section{DYSLIPIDEMIA OF OBESITY:}

In many overweight and obese patients hypertension, diabetes mellitus and hyperlipidemia occur together, greatly increasing the risk of atherosclerosis which may lead to heart attack, stroke and kidney diseases ${ }^{3}$. Adipose tissue lipid storage and processing capacity can be a key factor for obesity-related metabolic disorders. Morbidly obese patients have a lower gene expression of factors related with lipid uptake and processing ${ }^{11,12}$.

Paraoxonase-1 (PON1) plays a significant role in the prevention of obesity-related accelerated atherosclerosis by hydrolyzing lipid peroxides in oxidized low-density lipoproteins.

Obese subjects have increased oxidative stress and decreased PON1 activity ${ }^{13}$. Increased proportion of small, dense LDL and HDL particles are associated with the risk of coronary heart disease (CHD) ${ }^{1,2,3}$. Potential mechanisms that link small LDL particles to increased risk of vascular events are augmented oxidizability and increased permeability through the endothelial barrier. As for HDL, particle size, may involve the altered activity of lipases involved with the maturation and transformation of lipoproteins ${ }^{1,2,3,12}$.

Direct adipose tissue free fatty acid (FFA) storage may contribute to body fat distribution. There is evidence of reduced storage proteins in those with greater visceral fat ${ }^{14}$. The elevated Intramyocellular triglyceride (IMTG) concentration in obesity is accompanied by a increased capacity for fatty acid flux into the myocyte via an abundance of the key fatty acid transporter FAT/CD36 on the muscle membrane. Augmented intramyocellular fatty acid availability can increase triglyceride synthesis without altering the activity of key enzymes within the esterification pathway ${ }^{15}$.

Differential lipid redistribution through lipoproteins may affect body fat distribution. ${ }^{16}$

Potential adipocyte specific rate-limiting steps include 1) facilitated FA transport across the plasma membrane, mediated by proteins such as CD36, plasma membrane-associated fatty acid-binding protein (FABP[pm]), and fatty acid transport protein 1 (FATP1); 2) acylation,

3) final step of triacylglycerol formation ${ }^{14,15,16}$.

\section{EFFECT OF DISTRIBUTION OF BODY FAT AND INFLUENCE OF GENDER:}

Effect of body fat distribution on CVD can be explained by the hormonal and metabolic disturbances observed in abdominal obesity. As there are marked gender differences in regional body fat distribution, sex steroids are likely candidates for the determination of individual differences in body fat distribution and related metabolism ${ }^{17,18,19}$.

Abdominal obesity drives the progression of multiple cardiometabolic risk factors. This occurs through altered secretion of adipocyte-derived biologically active substances (adipokines), including free fatty acids, adiponectin, interleukin-6, tumour necrosis factor alpha, and plasminogen activator inhibitor-1. Typically, upper body obesity (android, 'apple shape' obesity) is more commonly found in men, whereas lower body obesity (gynoid, 'pear shape') is more commonly found in women. Upper body obesity receives contributions from adiposity in subcutaneous and intra-abdominal compartments. Individuals with increased waist circumference are found to have an atherogenic triad of elevated apolipoprotein B, fasting hyperinsulinaemia, and small, dense LDL, which are strongly associated with adverse cardiovascular outcomes ${ }^{17,18,19}$.

\section{OBESITY AND AUTONOMIC FUNCTIONS:}

Obese persons suffer from an increased mortality risk supposedly due to cardiovascular disorders related to either continuously lowered parasympathetic or altered sympathetic activation ${ }^{20}$.

Heart rate variation is reported to be reduced in obese individuals. Human obesity is characterized by marked sympathetic activation ${ }^{21}$. A 10 percent increase in body weight above an individual's usual weight is accompanied with a decrease in parasympathetic activity ${ }^{21}$.This is one mechanism for cardiac arrhythmias that accompany obesity ${ }^{21}$.

Leptin is an anorexigenic hormone that influences the feeding and satiety centres in hypothalamus. Neuropeptide Y (NPY) is orexigenic and NPY containing neurons have their cell bodies in the arcuate nuclei of hypothalamus and project to the paraventricular nuclei ${ }^{3}$.

Higher sympathetic activity in obese individuals is related to higher leptin levels. Leptin increases sympathetic activity in kidneys, adrenals and brown adipose tissue and results in increased vascular resistance and blood pressure ${ }^{22}$.At one time it was thought that adipocytes are the sole site of leptin production and release. Evidence from studies in experimental animals and human now indicates that leptin is also derived from non-adipose sites, one of these being the brain ${ }^{22}$. NPY concentration is increased in hypothalamus in obesity, and NPY has been implicated in effects of leptin on feeding behaviour. 
It has been suggested that there may be a two-way interaction between leptin and sympathetic nervous system. Leptin acting within the hypothalamus causes activation of the central sympathetic outflow and stimulation of adrenal medullary release of epinephrine. Conversely, sympathetic nervous system stimulation inhibits leptin release from white adipose tissue ${ }^{22,23,24}$. In obesity the sympathetic sensitivity of adipose tissue is reduced and this factor may underlie the dysregulation of leptin production and other adipose tissue secretions ${ }^{22,23,24}$

\section{OBESITY \& MENOPAUSE:}

Postmenopausal women have increased risk of metabolic syndrome including dyslipidaemia, insulin resistance, hypertension and cardiovascular diseases. The pathology may be a direct result of ovarian failure or an indirect result of central fat distribution associated with estrogen deficiency ${ }^{25}$.

Menopause is associated with reduced energy expenditure during rest and physical activity, an accelerated loss of fat free mass and alteration of adipose tissue metabolism and fat oxidation. Dysregulation of energy metabolism can induce an increase in total adiposity and a redistribution of fat in the abdominal region in postmenopausal women and increase fasting insulin levels. ${ }^{26}$.

Comparative studies in postmenopausal and perimenopausal women, have shown that despite similar fat cell size and $\beta$-adrenergic receptor and post receptor (dibutyryl-cAMP)-stimulated lipolysis, basal lipolysis is lower in gluteal adipose cells in postmenopausal as compared to perimenopausal women. AT-LPL activity in the gluteal region is higher than in the abdominal region and in the postmenopausal females ${ }^{27}$.

Menopause may result in endothelial dysfunction and increase in body weight and type II diabetes, causing an increase in sympathetic activation. Sympathetic activation can result in increased release of renin and Angiotensin II. Endothelial dysfunction is accompanied by reductions in nitric oxide (NO) and increases in endothelin, which both contribute to salt sensitivity of Blood Pressure and may lead to increased oxidative stress. All these factors may contribute to increase in renal vasoconstriction that may cause hypertension ${ }^{28}$.

\section{AGE AND BODY FAT:}

By 60 years body weight is 25 percent higher in males and 18 percent higher in females than in mature young adults. After 60 years, body weight decreases rapidly returning to values comparable to young adulthood. Effects of ageing on body composition are - increase in lipid fraction, loss of skeletal muscle and other components of lean body mass ${ }^{29}$. Ageing is a result of random mutations in the DNA of somatic cells, with consequent introduction of cumulative abnormalities. Changes in body composition with ageing reflect a decrease in lean body mass and an increase in body fat ${ }^{29,3}$.

\section{TREATMENT:}

The current NIH guideline recommend a decrease in calorie intake of 500 kilocalories per day for BMI > 25 but $<35$ and up to 1000 kilocalories per day for BMI $>35^{3}$. Dietary restriction increases LDL particle size, while endurance training augments HDL particle size, with minimal weight loss ${ }^{2}$. To decrease energy intake, diet should contain large quantities of cellulose ${ }^{2,3}$.

Significant weight loss can be achieved with increased physical activity ${ }^{1,2,3}$. Eating oat bran, which binds bile acids, increases the proportion of cholesterol that forms bile acids rather than new LDL. Resin agents can be used to bind bile acids in gut and increase their faecal excretion, thereby reducing cholesterol synthesis by the liver. Statins competitively inhibits hydroxymethylglutaryl- coenzyme A Reductase, a rate limiting enzyme in synthesis of cholesterol ${ }^{3}$.

Because of potential side effects, it is recommended that anti-obesity drugs only be prescribed for obesity where it is hoped that the benefits of the treatment outweigh risks. Orlistat is currently approved for long term use. It reduces intestinal fat absorption by inhibiting pancreatic lipase. Rimonabant, works via a specific blockade of the endocannabinoid system. Sibutramine, which acts in the brain to inhibit deactivation of the neurotransmitters. Phentermine, is used medically as an appetite suppressant. It is approved as an appetite suppressant to help reduce weight in obese patients when used for short-term. FDA officially approved lorcaserin for use in the treatment of obesity for adults with a BMI equal to or greater than 30 or adults with a BMI of 27 or greater who "have at least one weight-related health condition, such as high blood pressure, type 2 diabetes, or high cholesterol". Topiramate has been investigated for use in treating obesity, especially to reduce binge eating ${ }^{30,31,32}$. 
Bariatric surgery should be considered for all patients with a BMI of more than $40 \mathrm{~kg} / \mathrm{m} 2$ and for those with a BMI of more than $35 \mathrm{~kg} / \mathrm{m} 2$ with concomitant obesity-related conditions after failure of conventional treatment. For patients that are obese but not extremely obese, sleeve gastrectomy is a suitable operation with minimum risks. Two other most common surgical procedures to treat morbid obesity are gastric bypass and gastric banding $3,21,33,34$.

Stress is an important risk factor for the emergence of metabolic syndrome. There are numerous techniques available to reduce stress and produce relaxation. One of these, Jacobson's Progressive Muscle Relaxation technique, has shown positive clinical results and may be of help in reducing stress induced obesity 35

Conclusions: Obesity causes various harmful pathological changes in the body which needs to be studied elaborately to prevent and control the epidemic of obesity.

\section{REFERENCES:}

[1.] Elizabeth A Valente, Megan E Sheehy, Joshua J Avila, Julie A Gutierres, Matthew J Delmonico, Ingrid E Lofgren. The effect of the addition of resistance training to a dietary education intervention on apolipoproteins and diet quality in overweight and obese older adults Clinical Interventions in Aging 2011:6.235-241.

[2.] Yadav K, Krishnan A. "Changing patterns of diet, physical activity and obesity among urban, rural and slum populations in north India". Obes Rev 2008; 9 (5): 400-8. doi:10.1111/j.1467-789X.2008.00505.x. PMID 18627500.

[3.] Guyton AC, Hall JE. Dietary balances; Regulation of feeding; Obesity and Starvation; Vitamins and Minerals. Textbook of Medical Physiology. $11^{\text {th }}$ Ed. 2007; Elsevier, Saunders Inc, New Delhi, India: 843-857.

[4.] Mahbubur R, Abbey B. Accuracy of Current Body Mass Index Obesity Classification for White, Black, and Hispanic Reproductive-Age Women. Obstetrics \& Gynecology 2010; 115 (5):982-988.

[5.] WHO/IASO/IOTF. The Asia-Pacific perspective: redefining obesity and its treatment. Health Communications Australia: Melbourne, 2000.

[6.] Freedman DS, Thornton J, Pi-Sunyer FX, Heymsfield SB, Wang J, Pierson Jr RN, Blanck HM, Gallagher D. The body adiposity index (hip circumference $\div$ height(1.5)) is not a more accurate measure of adiposity than is BMI, waist circumference, or hip circumference. Obesity (Silver Spring). 2012 Apr 9. doi: 10.1038/oby.2012.81. [Epub ahead of print]

[7.] Varady KA, Bhutani S, Klempel MC, Kroeger CM. Comparison of effects of diet versus exercise weight loss regimens on LDL and HDL particle size in obese adults. Lipids in Health and Disease 2011; 10:119.

[8.] Cazettes F, Cohen JI, Yau PL, Talbot H, Convit A. Obesity-mediated inflammation may damage the brain circuit that regulates food intake. Brain Res. 2011; 1373 (10): 101-109.

[9.] Cable JC, Tan GD, Alexander SPH, O’Sullivan SE. The activity of the endocannabinoid metabolising enzyme fatty acid amide hydrolase in subcutaneous adipocytes correlates with BMI in metabolically healthy humans. Lipids in Health and Disease 2011; 10:129.

[10.] De Luis DA, M. Sagrado G, Aller R, Izaola O, Conde R. Relation of C358A polymorphism of the endocannabinoid degrading enzyme fatty acid amide hydrolase (faah) with obesity and insulin resistance. Nutr Hosp. 2010; 25:993-998.

[11.] Pasquali R, Patton L, Gambineri A. Obesity and infertility. Curr Opin Endocrinol Diabetes Obes. 2007;14(6):482-7.

[12.] Clemente-Postigo M, Queipo-Ortun o MI, Fernandez-Garcia D, Gomez-Huelgas R, Tinahones FJ, et al. (2011) Adipose Tissue Gene Expression of Factors Related to Lipid Processing in Obesity. PLoS ONE 6(9): e24783. doi:10.1371/journal.pone.0024783.

[13.] Aslan M, Horoz M, Sabuncu T, Celik H, Selek S. Serum paraoxonase enzyme activity and oxidative stress in obese subjects. Pol Arch Med Wewn. 2011; 121 (6): 181-186.

[14.] Asem H. Ali,Christina Koutsari, Manpreet Mundi, Mark D. Stegall, Julie K. Heimbach, Sandra J. Taler, Jonas Nygren, Anders Thorell, Lindsey D. Bogachus, Lorraine P. Turcotte, David Bernlohr, and Michael D. Jensen. Free Fatty Acid Storage in Human Visceral and Subcutaneous Adipose Tissue Role of Adipocyte Proteins. Diabetes 2011; 60:2300-2307.

[15.] Li M, Paran C, Wolins NE, Horowitz Am JF. High muscle lipid content in obesity is not due to enhanced activation of key triglyceride esterification enzymes or the suppression of lipolytic proteins. J Physiol Endocrinol Metab 300: E699-E707, 2011. doi:10.1152/ajpendo.00316.2010.

[16.] Søndergaard E, Nellemann B, Sørensen LP, Gormsen LC, Christiansen JS, Ernst E, Dueholm M, Nielsen S. Similar VLDL-TG storage in visceral and subcutaneous fat in obese and lean women. Diabetes. 2011;60(11):2787-91.

[17.] Despress J P, Moorjani S, Lupien P J, Tremblay A, Nadeau A, Bouchard C. Regional Distribution of Body Fat, Plasma Lipoproteins, and Cardiovascular Disease. Arteriosclerosis 1990; 10 (4): 497-511.

[18.] Despress J P. Abdominal obesity: the most prevalent cause of the metabolic syndrome and related cardiometabolic risk: European Heart Journal. 2006; 8:B4-B12.

[19.] Pouliot M C, Despress J P, Lemicux S, Moorjani S, Bouchard C, Tremblay. A et al. Waist circumference and abdominal sagital diameter: best simple anthropometric indexes of abdominal visceral adipose tissue accumulation and related cardiovascular risk in men and women. Am J Cardiol 1994;73 (7):460 - 468.

[20.] Laederach-Hofmann K, Mussgay L, Ru H. Autonomic cardiovascular regulation in obesity. Journal of Endocrinology 2000; 164: 59-66.

[21.] Maser R E, Lenhard M J, Irgau I, Wynn G M. Impact of surgically induced weight loss on cardiovascular autonomic function. One year follow -up. Obesity 2007; 15:364-369.

[22.] Guizar JM, Ahuatzin R, Amador N, Sanchez G, Romer G. Heart Autonomic Functions in Overweight Adolescents. Indian Pediatrics 2005; 42: 464-468.

[23.] Eikelis N, Lambert G, Wiesner G, Kaye D, Schlaich M, Morris M et al. Extra adipocyte leptin release in human obesity and its relation to sympathoadrenal function. Am. J Physiol. Endocrine Metab 2004:1-32.

[24.] Rayner D V. The sympathetic nervous system in white adipose tissue regulation. Proceedings of the nutrition society 2001; 60:357-364. 
[25.] Carr MC. The emergence of metabolic syndrome with menopause. J Clin Endrocrinol Metab 2003; 88:2404-2411.

[26.] Kimura T, Matsumoto T, Akiyoshi M, Owa Y, Miyasaka N, Aso T, et al. Body fat and blood lipids in postmenopausal women are related to resting autonomic nervous system activity. Eur J Appl Physiol 2006; 97:542-7.

[27.] Ferrara CM, Lynch NA, Nicklas BJ, Ryan AS, Berman DM. Difference in adipose tissue metabolism between postmenopausal and perimenopausal women. J Clin Endocrinal Metab2002; 87:4166-4170.

[28.] Coylewright M, Reckelhoff J F, Ouyang P. Menopause and Hypertension. An age- old debate. Hypertension 2008; 51:952-970.

[29.] Sieber FE, Pauldine R. Anesthesia for the Elderly. Miller's- Anesthesia, Edited by Ronald D Miller. Elsevier Churchill Livingstone, $6^{\text {th }}$ edition, 2005; II: 2436.

[30.] Nelson DL, Gehlert DR. Central nervous system biogenic amine targets for control of appetite and energy expenditure. Endocrine 2006; 29 (1): 49-60.

[31.] O'Neil PM, Smith SR, Weissman NJ, Fidler MC, Sanchez M, Zhang J, Raether B, Anderson CM, Shanahan WR. Randomized Placebo-Controlled Clinical Trial of Lorcaserin for Weight Loss in Type 2 Diabetes Mellitus: The BLOOM-DM Study.Obesity (Silver Spring). 2012; 20(7):1426-36.

[32.] Wilding J, Van Gaal L, Rissanen A, Vercruysse F, Fitchet, M. A randomized double-blind placebo-controlled study of the longterm efficacy and safety of topiramate in the treatment of obese subjects. International journal of obesity and related metabolic disorders: journal of the International Association for the Study of Obesity2004; 28 (11): 1399-1410.

[33.] Bult MJF, Dalen VT, Muller AF. Surgical treatment of obesity. Eur J Endocrinol 2008; 158(2) :135-145.

[34.] Nguyen N T, DeMaria EJ, Ikramuddin S, Hutter MM (2008). The SAGES Manual: A Practical Guide to Bariatric Surgery. Springer. p. 131. ISBN 0-387-69170-7.

[35.] LA Pawlow, PM O’Neil, RJ Malcolm. Night eating syndrome: effects of brief relaxation training on stress, mood, hunger, and eating patterns International Journal of Obesity 2003; 27: 970-978. 